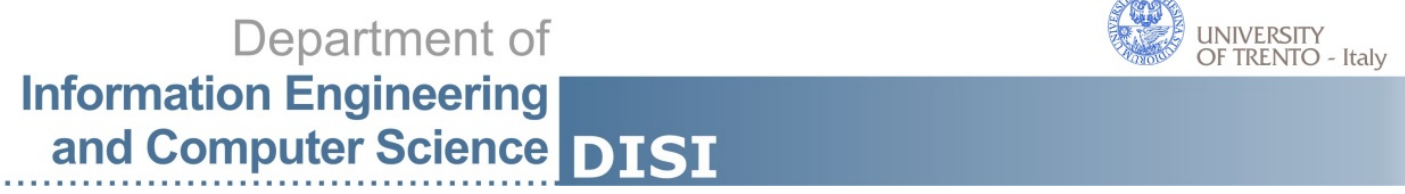

DISI - Via Sommarive 5 - 38123 Povo - Trento (Italy)

http://disi.unitn.it

\title{
SOCIAL INNOVATION IN DYNAMIC ENVIRONMENTS: ORGANISING TECHNOLOGY FOR TEMPORARY ADVANTAGE
}

\author{
Sandro Battisti \\ Politecnico di Milano \\ Department of Management, Economics and Industrial Engineering \\ Piazza Leonardo da Vinci, 32, 20133, Milan, Italy \\ Fax: +39 0223992720 \\ E-mail: sandro.battisti@polimi.it
}

July 2013

Technical Report \# DISI-14-007

Version 1.0

Published also: International Journal of Social Entrepreneurship and Innovation 


\begin{abstract}
A new challenge for public-private partnerships lies in gaining temporary advantage through social innovation, in order to operate within dynamic environments. This research explores social innovation enabled by technology, in order to build an empirical model that can be useful in addressing social needs of the citizens, while increasing temporary advantages for the companies. This research presents an entrepreneurial approach in which public-private partnerships can organise technology in order to develop and diffuse social innovation within dynamic environments. By employing this model, citizens can be empowered to participate in the joint construction of social innovation enabled by information and communication technology, in particular the phenomenon of shared data. The social entrepreneurship approach enables public-private partnerships to leverage shared data and obtain temporary advantages. This aids in developing innovative solutions to improve quality of life of citizens while it enables companies to succeed in dynamic environments.
\end{abstract}

Keywords: Social innovation; service innovation; technology innovation; social entrepreneurship; dynamic environments; public-private partnership; information and communication technology; user involvement; value creation; early adoption; temporary advantage.

References to this paper should be made as follows: Battisti (2013). Social innovation in dynamic environments: organising technology for temporary advantage, Int. J. Social Entrepreneurship and Innovation, Vol. 2, No. 6, pp. 504-524.

Biographical notes: Sandro Battisti is a PhD Candidate in Management, Economics and Industrial Engineering at Politecnico di Milano. His thesis is on innovation management and new service development based on information and communication technologies. His research interests are centred on service innovation, social innovation, open innovation, social entrepreneurship and technology diffusion. He holds an MBA from the IBGEN and a Bachelors' degree in Electronic Engineering from the PUCRS, both in Brazil. He has ten years of experience in management of telecommunication services in Brazil. $\mathrm{He}$ is currently a member of Trento RISE, a core partner of the EIT ICT Labs. 


\section{INTRODUCTION}

Social innovation is increasingly explored by companies under exceedingly dynamic conditions. These conditions are characterised by rapid changing of customer preferences and uncertainty about competitive solutions (Bhattacharya et al. 1998). The main problem that must be taken into account by companies is the instability of competitive advantage and its unforeseeable duration, within dynamic environments, as suggested by Davis et al. (2009).

Public-private partnerships (PPP) can be structured to support the development of information and communication technology (ICT) in order to obtain the necessary temporary advantage required in dynamic environments, and thus to compete through social innovation instead of innovation that addresses only business goals. D'aveni et al. (2010) defined the concept of temporary advantage as a short period in which organisations can successfully compete, evolve and survive. Thus, organisations are able to find alternative ways to adapt to fast changing environments, in order to explore social innovation. From this perspective, social innovation can be viewed as innovation that copes with economic and social needs, in particular innovative services that meet the needs of their customers (Ratten, 2012).

This research is based on the following definition of social innovation: "innovations that are social both in their ends and in their means. In other words: it covers new ideas (products, services, and models) that simultaneously meet socially recognized social needs (more effectively than alternatives) and create new social relationships or collaborations, that are both good for society and enhance society's capacity to act” (Mulgan, 2012:35).

From this perspective, this research investigates social innovation enabled by ICT, in particular the phenomenon of shared data. This research defines shared data as the data obtained by a public-private partnership, where the scope covers collection, integration and elaboration of this data into service solutions to aid in improving quality of life of citizens; while its used to explore new business opportunities within private companies. This data is classified into three categories: open data, big data and social data. Open data is related to information obtained from the public and private companies that is available on website catalogues to organisations. Big data is mainly a large amount of information from private sources that are extracted to be used in the development of innovative services, which can be done via partnership established between small-medium enterprises (SME) and large companies. Social data is related to the information available on large social networks, such as Twitter and Facebook, which can be obtained by PPPs through the use of ICT.

This phenomenon of shared data enables public-private partnership to deliver new services to citizens, in order to create new social values for the entire society. In particular, from the open 
data perspective, O'Reilly (2010) explained that PPP can explores the same openness related to transparency that also enables innovation, by developing services based on open data. Moreover, this is supported by PPP, where software developers build new service applications based on shared data. From this perspective, Ding et al. (2012) explained that open data is designed to promote collaboration between governments, companies and citizens. Open data can be viewed as the basic data to be introduced in the development of social innovation. Integration of open data with big and social data, could allow the development of innovative added-value services for the improvement of the quality of life of citizens, all the while increasing temporary advantage for companies.

In early phases of the social innovation process, specific environments can be used by companies to test innovation and thus accelerate the growth of SMEs. These environments are called living labs. From these living labs, PPP can develop specific organisational processes to realise the early adoption of innovation. This research explores the definition of living labs proposed by Katzy et al. (2012:2) i.e. "innovation intermediaries that coordinate network partners for the execution of innovation processes with engagement of end-users for which they provide the technical and organisational infrastructure".

PPP can play a central role in organising and managing social innovation thorough collaborative processes. These processes involve complex social interactions that could be beneficial in resolving conflict situations and misunderstandings in communications, throughout the innovation process (Sundbo and Toivonen, 2011). PPP could potentially explore new business opportunities, in order to generate results for the well-being of citizens, while increasing the profits of companies and enable them to achieve temporary advantage. From this perspective emerges the need to develop appropriate new models of social innovation enabled by shared data, when considering PPP within dynamic environments. Moreover, Davis et al. (2009) suggested that management in unpredictable environments is different and more difficult than in technology markets. This research particularly expands the social entrepreneurship and innovation fields, in particular regarding the development of innovative services solutions based on technology, as suggested by Ratten (2013). More specifically, this work contributes with a model for management of social innovation enabled by ICT in dynamic environments toward advance knowledge. The empirical field, in which this model has been created, is the Trentino territory in the north of Italy. From this perspective, this research investigates the following questions:

i. How are public-private partnerships organised in order to develop social innovation, enabled by the shared data, within dynamic environments?

ii. How can public-private partnership support small-medium enterprises, so as to guarantee temporary advantage within dynamic environments? 
This paper is organised in the following five sections. Section 2 presents the theoretical framework, followed by the combined qualitative methodology based on case study and clinical inquiry research in section 3 . Section 4 presents the data analysis with examples of social innovations. The results, regarding the presentation of a model for social innovation in the context of dynamic environments and propositions for further research, are discussed in section 5. Finally, section 6 presents discussion and conclusion including implications for theory and practices.

\section{THEORETICAL FRAMEWORK}

The current understanding of social innovation suggests that the users are central actors in the innovation process (e.g. Mulgan, 2012); and that the innovation output could combine the creation of economic and social values (Austin et al. 2006). Social entrepreneurship, in particular, is a new way of addressing social needs, which explores business opportunities and market-based strategies (e.g. Miller et al. 2012 and Okpara and Halkias, 2011).

Social needs have been increased due to the environmental changes such as the huge financial crisis and the constant budget cuts for the innovate projects in the private and public sectors. This fact must be taken into consideration in the development of social innovation by public-private partnerships. In order to cope with constantly growing social needs, new ways of partnerships could support SMEs in the achievement of temporary advantage in conditions of rapidly environmental changes. Furthermore, Battisti (2012) suggested that the research in the field of social innovations, and in conditions of dynamic environments, must be based on at least four drivers (i.e. living labs, social construction, knowledge-intensive, hyperturbulence), which has been adapted to be used in this research, as presented in Table 1.

Table 1 Drivers of social innovation in dynamic environments

\begin{tabular}{l|l}
\hline \multicolumn{1}{c|}{ Drivers } & \multicolumn{1}{c}{ Briefly description } \\
\hline 1. Living labs & $\begin{array}{l}\text { Cope with economic and social needs of specific local territories, } \\
\text { such as hidden needs of citizens, and emerging business } \\
\text { opportunities. }\end{array}$ \\
\hline 2. Social construction & $\begin{array}{l}\text { Be socially constructed with citizen's empowerment, such as expert } \\
\text { users, policy makers, non-expert users, or relevant social groups. }\end{array}$ \\
\hline 3. Knowledge-intensive & $\begin{array}{l}\text { Be developed in collaboration with knowledge-intensive } \\
\text { companies, such as high-tech companies that are specialised in } \\
\text { developing innovation enabled by ICT. }\end{array}$ \\
\hline Be Hyperturbulence & $\begin{array}{l}\text { Benstructed through in-depth social processes, under conditions } \\
\text { of hyper turbulence of markets and technologies, such as the } \\
\text { dynamic environments. }\end{array}$ \\
\hline
\end{tabular}

In order to create a clear understanding about innovation with social and economic values, this research explores two streams of the literature in the next section. First, value creation and 
user involvement is discussed. And then, the temporary advantage and early adoption is explained.

\subsection{Value creation and user involvement}

Social innovations are being increasingly developed by networks of companies, more specifically SMEs. From this perspective, PPPs play a fundamental role in supporting the growing of the SMEs, in particular within living labs, in order to cope with continuously increasing social problems faced by local communities. In social innovation, the term social is the type of service for which an innovation is developed, as explained by Harrisson et al. (2010). From this perspective 'social' can also refer to a service designed for a specific community, in specific contexts, in order to cope with social problems. Moreover, social innovation can be viewed as a set of services designed to respond to the needs of people that remain unsatisfied in explicitly defined contexts, in order to contribute to the well-being of the whole community, composed by several stakeholders of different mind-sets.

In order to understand stakeholders' needs in social innovation, Bates (2012) suggested that the problem must be defined in detail and with precision, which can be based on the clear understanding of the political, cultural and social contexts. Furthermore, Mulgan (2012) argued that social innovation must promote well-being of citizens, as a social process as well as a final social solution for citizens, in order to be accepted as social innovation by the entire social ecosystem.

Social innovation involves multiple stakeholders, which poses another challenge that could be managed by PPP. Bessant (2009) suggested that this challenge could be addressed by developing partnerships with user in order to sustain competitive advantages. However, Tidd (2009) argued that managers must be engaged in coping with social challenges rather than deal with only pressing issues regarding the companies' market competition. From this perspective, Perks et al. (2012) suggested that co-creation of innovation process is a complex endeavour, and also argued that SMEs should be more flexible than large companies in acting as a hub-company for the development of innovation.

In the same way this argument is supported by Jespersen (2011), who discussed that companies can increase competition by exploiting the large use of online communication channels not only to interact with users but also to keep them involved throughout the innovation process. The creation of communities is crucial for distributed co-creation of social innovation with customers in order to support companies to achieve innovation success in unpredictable market conditions, as also supported by Giannopoulou et al. (2011). Moreover, Bogers and West (2012) suggested that these communities are held responsible for building dynamic interaction between several stakeholders within a value network. 
Customers are members of the ecosystem, which aids in maximising the value creation of the all network actors and the improvement of satisfaction levels, as suggested by Bates (2012). Within dynamic environments, the customer satisfaction changes over time. Innovations must follow these changes in order to achieve higher levels of value creation from the whole ecosystem, such as costumers, large companies, small-medium enterprises, policy makers, public authorities and relevant social groups.

For addressing the ever increasingly requirement of users, Nicholls and Murdock (2012), suggested that in order to cope with the creation of social value for users, companies can develop social innovation focused on defining solutions for social problems rather than the services that purely address the economic needs of the stakeholders. In addition, Harrisson et al. (2010) suggested that innovation without clear social value cannot be considered social innovation. In this sense, the PPP responsible for the innovation process must take into consideration the social relations of the main actors within the ecosystem where developing social innovation is concerned.

The value creation of the social innovation into the society depends on the type of engagement of users in the process, as suggested by Lehtonen and Tuominen (2011), once users can be empowered by companies to generate value creation, while users participate into innovation process. Moreover, Borges et al. (2010) argued that costumers can perform different roles in the innovation processes and these roles depend on the expectations of companies regarding the individual participation of users.

The roles of users depend on the public-private partnership configuration as well as on the communication channels between companies in the innovation processes, as argued by Hsieh and Tidd (2012). They also argued that the success of any innovative project depends on high level of knowledge sharing and the use of this knowledge to improve the innovation and increase competitive advantage. This knowledge flow is facilitated when social innovation is co-created in the living labs. An example from the open source software explores the case of open innovation networks of Iphone and Android, developed by Remneland-Wikhamn et al. (2011), who suggested that openness for the user means to give them the freedom of control over their experiences.

Furthermore, Wouters (2010) argued that the construction of a shared understanding of customer values can support companies in the investment of innovation with very high potential to succeed within dynamic environments. Moreover, social innovation increases the possibility for companies to succeed in dynamic environments, more specifically since companies are involved in learning from relevant social groups (Battisti, 2012), in which PPP play a fundamental role in creating a virtuous cycle of innovation with citizens. 
The value created by the social entrepreneurship activities developed by SMEs could be measured in terms of economic and social impact (Ormiston and Seymour, 2011). In particular, in the context of Italian scenario of social entrepreneurship, Scarlato (2012) stated that traditionally Italy is a country with several co-operative movements, and also suggests that the business development, within the regional environments, could be addressed by improving economic and social conditions.

\subsection{Temporary advantage and early adoption}

Social innovation is playing a central role within dynamic environments, more so since it enables the involvement of citizens in the innovation process, which facilitates the achievement of competitive advantage of PPPs. From this perspective, Davis et al. (2009) defined that dynamic environments are characterised to present four main variables: velocity, the rate at which new opportunities emerge; complexity, the number of features of an opportunity that must be correctly executed to capture an opportunity; ambiguity, the lack of clarity such that it is difficult to interpret opportunities; and, unpredictability, the amount of turbulence in the flow of opportunities such that there is less consistent pattern.

In order to enable companies to succeed in dynamic environments, Sirmon et al. (2007) suggested that the top-level managers can view companies as a system of capabilities that develop strategies according that cater their own capabilities within the market and environmental contexts. The four variables and the capability based approach previous presented, have a direct influence on the competitive advantage of companies. Moreover, managing structures to adapt to the fast changing of environments can guarantee temporary advantage (D'aveni et al. 2010). From this perspective, ICT can support companies to cope with social innovation within dynamic environments, once ICT could be shaped socially through the need of actors such as social, organisational, economic and political. More specifically, the main capabilities of companies that are directly related to ICT can support them in the rapid development and the use of communication channels in the commercialisation of innovations.

Under conditions of competitive forces that cause high pressure within companies, Sheremata (2000) found that successful innovation requires organisational structures that increase the quantity and quality of knowledge, as well as the integration of this knowledge into collective action realised by the people. Taking into consideration an incremental view of innovation within companies, Posen and Levinthal (2012) argued that under the conditions of environmental change a possible alternative for companies to obtain success could be the exploitation of existing knowledge and opportunities inside the organisation, rather than keeping focus solely on the exploration of new market opportunities. Furthermore, Sheremata (2004), argued that innovation depends on the characteristics of the target market and the availability of technology, and suggested that radical innovation is more likely to be profitable than incremental innovation. 
For achieving temporary advantage within dynamic environments, PPP must take into account the early adoption of innovation by community of users. In order to develop, manage, and aid, in the early adoption of service innovation (Talke and Hultink, 2010), SMEs can explore the ecosystem provided by living labs. Furthermore, SMEs can organise appropriate partnerships in order to explore the diffusion of this service innovation in new markets. In the same way, Dell'Era and Verganti (2011) argued that speed and contagion can be considered as important constructs to take into consideration for the diffusion of innovation. In addition, Chiesa and Frattini (2011) suggested that early adoption can support the success of the innovation in hightechnology markets.

From this perspective, early adoption can be enabled by living labs as innovation intermediaries, as suggested by Katzy et al. (2012). Moreover, living labs can facilitate the set-up of crowdsourcing platforms, which can ensure co-creation and then early adoption of innovation. From an extensive analysis of the definitions of crowdsourcing in the current literature, EstellésArolas and González-Ladrón-De-Guevara (2012), defined crowd sourcing as: "crowdsourcing is a type of participative online activity in which an individual, an institution, a non-profit organization, or company proposes to a group of individuals of varying knowledge, heterogeneity, and number, via a flexible open call, the voluntary undertaking of a task". Furthermore, Colombo et al. (2013) suggested that web-based intermediaries that offer crowdsourcing services can support companies in increasing competitive advantage. Moreover, as argued by Martin and Scott (2000), public authorities can provide sustainable economic support for the growth of SMEs or start-up companies in specific local territories, such as living labs.

SMEs can be supported in the development of social innovation through funding obtained from several kinds of sources, in a way defined as crowdfunding. In the context of PPP, crowdfunding can give incentive to users to participate in the network of innovation and at the same time adopt the innovation in early stages. Crowdfunding is a way to obtain micro-funding from a disperse crowd of people from several purposes. This point of view enables SMEs to leverage the development of innovation from a mix of entrepreneurship and social network participation (Ordanini et al. 2011). Mollick (2014) defined crowfunding as "a novel method for funding a variety of new ventures, allowing individual founders of for-profit, cultural, or social projects to request funding from many individuals, often in return for future products or equity".

In this context, Belleflamme et al. (2013) argued that crowdfunding is associated with experiences within communities that can generate huge benefits from the participants' network of relationships. Moreover, Miller et al. (2012) suggested that the compassion of users into the innovation process increases the possibility of users to stay engaged in social entrepreneurship. Furthermore, Cameron (2012) found that the mapping of ecosystems could help make the entrepreneurs aware of risks and opportunities that emerge within the environment. 


\section{RESEARCH METHODOLOGY}

The research methodology was divided in two parts, clinical inquiry research (e.g. Schein, 2008), and, case study research (e.g. Yin, 2009), which will be discussed in detail in this section. The research was carried out from January-2012 to July-2013.

The theoretical attributes for the data analysis are presented in Table 2. From these categories, the research aims at building a social innovation model to support companies in the development of business within dynamic environments. At the same time these categories can enable an appropriated way to address value creation, in order to cope with social needs of citizens.

Table 2 The theoretical attributes

\begin{tabular}{|c|c|c|}
\hline Attributes & The suggested description & Main references \\
\hline $\begin{array}{l}\text { 1. Value } \\
\text { creation }\end{array}$ & $\begin{array}{l}\text { Companies can develop social innovation focused on } \\
\text { coping with solutions to social problems and address } \\
\text { the economic needs of the stakeholders. The sharing } \\
\text { of a common understanding of the customer value } \\
\text { (i.e. social and economic), within the PPP can support } \\
\text { the success of the innovation within dynamic } \\
\text { environments. }\end{array}$ & $\begin{array}{l}\text { Perks et al. (2012), } \\
\text { Mulgan (2012), } \\
\text { Nicholls and Murdock } \\
\text { (2012) and Bogers } \\
\text { and West (2012) }\end{array}$ \\
\hline $\begin{array}{l}\text { 2. User } \\
\text { involvement }\end{array}$ & $\begin{array}{l}\text { Companies can empower the user to create value } \\
\text { thorough participating in the innovation process. The } \\
\text { success of an innovative project depends upon high } \\
\text { level of knowledge shared between users and the PPP } \\
\text { and consequently the use of this knowledge in the } \\
\text { production of social innovation. }\end{array}$ & $\begin{array}{l}\text { Borges et al. (2010), } \\
\text { Lehtonen and } \\
\text { Tuominen (2011), } \\
\text { Hsieh and Tidd } \\
(2012) \text { and Battisti } \\
(2012)\end{array}$ \\
\hline $\begin{array}{l}\text { 3. Temporary } \\
\text { advantage }\end{array}$ & $\begin{array}{l}\text { Companies that operate within dynamic environments } \\
\text { must take into account the velocity, complexity, } \\
\text { ambiguity and unpredictability of environments. Top- } \\
\text { level managers can view companies as a system of } \\
\text { capabilities, in order to successfully compete, evolve } \\
\text { and survive while temporary advantage is achieved. }\end{array}$ & $\begin{array}{l}\text { Sheremata (2004), } \\
\text { Sirmon et al. (2007), } \\
\text { Davis et al. (2009) } \\
\text { and D'aveni et al. } \\
\text { (2010) }\end{array}$ \\
\hline $\begin{array}{l}\text { 4. Early } \\
\text { adoption }\end{array}$ & $\begin{array}{l}\text { Companies involved in social innovation adopt } \\
\text { understanding social needs as the main driving force. } \\
\text { It increases the possibility of social innovation } \\
\text { diffusion, considering that speed and contagion } \\
\text { enable early adoption within living labs. This process } \\
\text { is facilitated by crowdsourcing and crowdfunding } \\
\text { strategies. }\end{array}$ & $\begin{array}{l}\text { Chiesa and Frattini } \\
\text { (2011), Dell'Era and } \\
\text { Verganti (2011), } \\
\text { Mollick (2013) and } \\
\text { Belleflamme et al. } \\
\text { (2013) }\end{array}$ \\
\hline
\end{tabular}

The unity of analysis was the organisation level in the Trentino territory in Italy. This has been explored during an in-depth study of five organisations involved in public-private partnerships around the context of social innovation in Trentino, which is detailed as follows:

i. Autonomous Province of Trento (PAT): It is divided into 217 municipalities with approximately 530.000 inhabitants, localised in the north of Italy. In terms of legislation power, PAT is the highest-level of public authority in the Trentino territory, which 
imposes regional laws and is also responsible for fostering territorial ecosystem of social innovation enabled by ICTs. They are also responsible for enabling and managing the ecosystem of services enabled by open data. They support the EIT ICT Labs in Italy, in close collaboration with Trento RISE co-location centres, where several companies develop service innovation to aid in improving the quality of life of citizens (www.provincia.tn.it).

ii. EIT ICT Labs Italy: It is the organisation responsible for guiding the knowledge and innovation community (KIC) in Italy, in order to foster innovative services enabled by ICT. The core partners are: Trento RISE Association, Telecom Italia Spa., and Engineering Ingegneria Informatica Spa. The partners collaborate in sharing knowledge and bringing about innovation to improve the quality of life of the people. The core areas of innovation are: Digital Cities of the Future; Health \& Well-Being; Smart Energy Systems; Smart Spaces and Intelligent Mobility, and Transport Systems. The EIT ICT Labs in Italy was founded in January 2012 and is one of the six centres of excellence in Europe, including Germany, The Netherland, Finland, Stockholm and France, which support 80 research centres, industrial companies and technical universities around Europe (www.eitictlabs.eu).

iii. Trento RISE Association: It is the Trentino innovation centre for excellence in ICT and is focused on the management of innovative projects to improve the quality of life of people and at the same time support entrepreneurial initiatives (start-ups and SMEs). TRISE was established in 2010 by two highly qualified ICT players in Italy: the Department of Information Engineering and Computer Science-DISI (http://disi.unitn.it/) of the University of Trento, and the Centre for Information Technology of the Bruno Kessler Foundation-FBK (http://ict.fbk.eu). It is responsible for business modelling activities within projects with the EIT ICT Labs in Italy and also manages the core living labs activities around the six centres of excellence of EIT ICT Labs in Europe. TRISE specialises in service innovation areas such as: health and well-being, sustainable environment, tourism management, cultural heritage and smart energy system (www.trentorise.eu).

iv. Telecom Italia Spa.: It is the major Italian telecommunication operator and was established in 1964. They employ more than 50.000 people. They hold especial agreements with Trento RISE founders to develop the Trentino Open Living Data (TOLD) and the Mobile Territorial Labs (MTL). In the Trentino territory, they provide specialised services in three main areas: Network structures based on optical fibre; software development and the Skil laboratory (Semantics and Knowledge Innovation Laboratory). The Skil Lab last is co-located with the EIT ICT Labs in the city of Trento (http://skil.telecomitalia.com). Skil Lab focuses on development of a bridge between the academic research in ICT and industrial innovation. The commercialisation of innovation 
occurs throughout the large domestic and media channels of the Telecom Italia Group at the national level, as well as in Brazil and Argentina (www.telecomitalia.it).

v. Engineering Ingegneria Informatica Spa.: It is an international player of Information Technology domain and is the first Italian company of software and services and stands among the top 10 European ICT groups. It was established in 1980 and currently employs 7.000 people in Italy, Belgium, USA, Brazil and Argentina. They are also core partners of the EIT ICT Labs in Italy, thorough the laboratory Estro (Engineering Society and Territory Research Office), established in the co-located centre of the EIT ICT Labs in the city of Trento. Engineering holds an integrated offering of ICT services across the entire value chain of software solutions for companies: consulting, systems and business integration, outsourcing services, products and industry solutions. They manage the Spago Group, responsible for open source solutions (www.spagoworld.org). They are the company responsible for providing innovative services in tourism and cultural heritage domains in Trentino, through a model based on the PPP alongside other SMEs in Trentino territory (www.eng.it).

The combined methodology was applied in order to increase the quality of data collection thorough interactions between the researcher and managers during the entire research period. The two phases of the research process are detailed as follows: in the "clinical inquiry research" part, the researcher played a central role in the inquiry process thorough the interpretation of needs of the fifteen interviewed managers presented in Table 3. These managers are responsible for enabling initiatives regarding social innovation enabled by shared data in Trentino.

Table 3 The organisations and managers

\begin{tabular}{l|c|c}
\hline \multicolumn{1}{c|}{ Organisations } & Managers'job title & $\begin{array}{c}\text { Years of experience in } \\
\text { ICT \& Innovation }\end{array}$ \\
\hline 1. Autonomous Province of & & 26 years \\
Trento & Innovation Director & 11 years \\
& Program Manager & 17 years \\
\hline 2. EIT ICT Labs Italy & Project Manager & 41 years \\
& Node Director & 33 years \\
& Business Developer & 29 years \\
\hline 3. Trento RISE Association & Project Coordinator & 28 years \\
& Cnnovation Director & 21 years \\
& Project Manager & 17 years \\
\hline 4. Telecom Italia Spa. & Innovation Director & 9 years \\
& Project Manager I & 9 years \\
& Project Manager II & 6 years \\
\hline 5. Engineering Ingegneria & Innovation Director & 33 years \\
Informatica Spa. & Project Manager I & 19 years \\
& Project Manager II & 19 years \\
\hline
\end{tabular}

The researcher participated in the decision-making meetings of the PAT and Trento RISE and collected data during formal meetings that occurred at least twice a week, and each of these was 
about two or three hours long. The main goal of the meetings was to understand and propose social innovation solutions, from the shared data, explored by organisations established in Trentino. The dynamic nature of the relationship between the researcher and the managers acted as the base of the inquiry process for systematic data collection. In addition, were carried out the participation in the innovation process, in-depth interactions with several employees of the organisations, and also participation in decision making-group.

In the "case study research" part, fifteen in-depth interviews were conducted with the managers of the five organisations around the living labs of social innovation enabled by shared data in Trentino. These interviews were conducted and recorded by the researcher and lasted between one to two hours, each. Furthermore, the secondary data collection was based on annual reports, internal archives (i.e. project description of the organisations) and websites of the organisations.

\section{Data analysis}

From the data collected through the understanding of how the five organizations joint develop social innovation, it was verified that Trento RISE is the hub-organisation in fostering the innovation activities within the Trentino territory. Shared data comes from three large projects in Trentino. The two main projects are managed by Trento RISE, and are defined as "Flagship" (i.e. core projects lasting at least 3 years and involving more than thirty people full-time, starting in 2012), named Open-Big Data and Smart Campus Lab. In addition, the project Trentino Open Living Data (TOLD) managed by Telecom Italia-Skill Lab, was analysed by the researcher. This is a core project in the context of the EIT ICT Labs Italy that has been planned to last 3 years starting in 2012. The details of these three projects are as the following:

i. Open-Big Data Flagship: It is a large ICT platform aimed at making public sector information accessible to people, in order to enhance economic growth and regional development, by supporting SMEs. The service solutions are developed in collaboration with local and private companies, and with citizen participation. The co-creation process for the development of innovative services is centred on the improvement of the quality of life of the people. At the same time, the project also creates a technology infrastructure to support growing SMEs within dynamic environments. The social needs addressed by this lab are dependent on first understanding citizens' needs, and then developing services to address these requirements. For instance, the services are based on mobile apps to be used by some of the families within the Trentino territory. (Platform websites: www.dati.trentino.it and www.trentorise.eu)

ii. Smart Campus Lab Flagship: It is an ICT platform that creates a social and technological environment to aid in the co-creation of services, with and for the people. In 
addition, this brings-forth a social and technical environment for collaborative service design. This platform is an open lab model of a smart city (i.e. integration of several stakeholders from public, private, non-profit organisations and citizens, for the development of innovative services to address the needs and quality of life of the people). The social needs addressed by this lab include social problems of students, researchers and employees, when they are considered as the users, designers and sometimes even developers of the services to conceive solutions in order to solve their own problems. (Platform website: www.smartcampuslab.it)

iii. Trentino Open Living Data (TOLD): It is an initiative that aims at creating a platform for collecting, analysing and sharing data around the context of the Trentino living lab. The shared data explored in this lab is related to energy consumption, telephone network activity, and highway traffic. From the analysis of shared data, private organisations (i.e. SMEs and large companies) collaborating with Telecom Italia, can develop service for the local communities and at the same time increase the decision support systems of companies. The project has been designed to provide to the PPP with an understanding of emerging social problems and solution proposals for these problems within the publicprivate partnerships, in collaboration with the users. TOLD enables companies to share data with the PPP in order to maximize the social and the economic value for companies and citizens. (http://skil.telecomitalia.com/)

The PPP guided by Trento RISE, in collaboration with the other four main organisations, enabled the three large projects to integrate the efforts in developing innovative service applications. Several SMEs (i.e. local companies specialised in the development of ICT) can be engaged in the EIT ICT Labs, in order to develop social innovation (i.e. mobile apps available in the Google Play; that cope with social problems of the citizens of the Trentino Territory). Four examples of social innovation currently being developed in collaboration with SMEs in the Trentino territory are as following:

i. Family living experience: It integrates a set of services into a single mobile app, to improve the quality of life of families as they carry on with their daily life activities in the city. The main goal of this setup is to measure and manage the time a family spend together or the time parents spend during work activities. The innovation also provides citizens with a list of summer activities dedicated to youth and family. The innovation provides information to citizens about: changing diapers to families with infants; places for breastfeeding, bus routes, special paths recommended for trekking with family; educational and cultural events for families; and activities involving youth and families during the summer. The PPP manages a network of 45 companies that are certified as partners that provides shared data to the mobile application in order to send updated information to the families. These companies are considered "family friendly". 
ii. Skiing enhanced services: It provides support for tourists and citizens in the Trentino territory. This service provides the users with information regarding new interesting places that offer unique perspectives on the mountains, lakes and other points of interest. The innovation facilitates users in exploring new areas with their families. This could, for instance, be achieved through the use of special areas for children's entertainment, which were established based on the frequency of use of each ski-run. The service could be used to track the experience of users and their families, while at the same time store all the data on a server when the users ski on different routes. The service also could be useful for measuring performance and experiences, and to improve the athletic competition capacity and family experience within these environments. The shared data used in these services can be obtained from sensors around the environment, and can be integrated with social data from social network platforms. The real-time data from these sensors is crucial for professional skiers and also for the improvement of the quality of life when skiing with family, and aids especially in reducing accidents.

iii. Cycling and trekking in safe conditions: It provides update on the state of the roads to cyclists, in order to assist them in the management of activities during normal as well as emergency situations, for instance, avalanches and weather conditions. This service also uses datasets coming from several different sources, such as mobile telecommunication companies, about the traffic of mobile phones based on the number of bikers on a road. This could be remarkable in the prevention of bottlenecks during public events. In order to design new paths to be shared with in-line skaters, scooters, skateboarders, and pedestrians, the service provides better conditions for a user cycling and trekking experience. This could lead to reduction in the number of car-bike collisions, for example. The information, about the number of bikes present on the road at a given time, could permit bicycles to be carried on public transport integrated with tourism and exploration, or sightseeing on bicycle for leisure. This could be useful in informing the police patrolling in parks on bicycles in order to aid in reduction of theft and increase security.

iii. Optimising transportation in the city: It is useful in defining routes to control traffic flow and save fuel, aid in reducing stress for people stuck in traffic, reduce traffic jams, and eventually aid in improving quality of life of people. The success of this social innovation could be achieved through the increasing of the quality of life of people when they are driving the car or taking the bus. In addition, citizens can plan their trips in the city of Trento in Italy and receive updates on the events around their residence, university, and leisure activities. Citizens can send and receive notices about journey delays and traffic jams, save and monitor their frequent routes, and search for current and future events.

The shared data leveraged by mobile applications in web-markets could be considered as a support mechanism for the growth of small-medium enterprises in living labs. This enables 
public-private partnerships to build an open innovation network, which is capable to explore business opportunities under conditions of dynamic environmental changes. In addition, shared data enables the development of service innovation for improving the quality of life of citizens through partnerships with private companies, research centres, SMEs and relevant social groups.

The creation of value for the whole society is one of the main challenges that have been explored by the PPP through fostering innovation enabled by shared data in the Trentino territory. More specifically, open data constrains imposed by the European Commission (EC) force in particular local public authorities (i.e. in this case, the Autonomous Province of Trento), to develop new local policies for government transparency and economic growth of the territory, in order to regulate the re-use of data of the public organisations in Trentino. It enables the fostering of sustainability, and achievement of temporary advantage for SMEs, especially during the long time period of economic crisis. In this sense, open data could be considered as a key driver for social innovation and sustainable growth, once the PPPs start to increasingly support social entrepreneurship through innovation centres of excellence, such as Trento RISE.

For instance, in PPP the innovation is designed, developed and managed alongside research centres, SMEs, and citizens as a collaborative and social process. These initiatives of social innovation have been specifically developed in the Trentino territory, by SMEs based on three pillars of open data, i.e. transparency, accountability and participation. When the open data is integrated with big data and social data, the process of development of new services increases the collaboration with users, which enable customised niche services that facilitate the achievement of the temporary advantage of SMEs in the commercialization of the mobile applications in web markets, such as Google Play (https://play.google.com/store) and Apple Store (http://store.apple.com).

\section{RESULTS}

The phenomenon of shared data within the Trentino territory in Italy enables to understand how PPP develops appropriate structures and social processes with citizens and SMEs, in order to obtain social innovation success. The joint creation of innovations by SMEs and the PPP enables the development of solutions to improve the quality of life of citizens and increase companies' temporary advantage. This is one of the most relevant challenges that the PPP focus on in order to manage the development of a sustainable model of social innovation in a shorttime period.

From this perspective, citizens and SMEs can suggest improvements for service innovation to PPP that come from the innovative communities. Within the three major projects, which have been described and analysed earlier in this work, PPP can manage the input received by user information, in order to introduce changes into the innovation process. PPP also can act in real 
time in a way that might not be possible using traditional models of production of innovation.

This research presents a model for social innovation enabled by shared data, as shown in Figure 1. This model presents the process in which PPP can organise the development of social innovation within dynamic environments. It is based on seven phases that PPP can follow in order to cope with social innovation enabled by shared data. The model enables the PPPs to develop social innovation in order to enhance the well-being of citizens and at the same time explore economic opportunities within dynamic environments.

Figure 1 The model for social innovation enabled by shared data

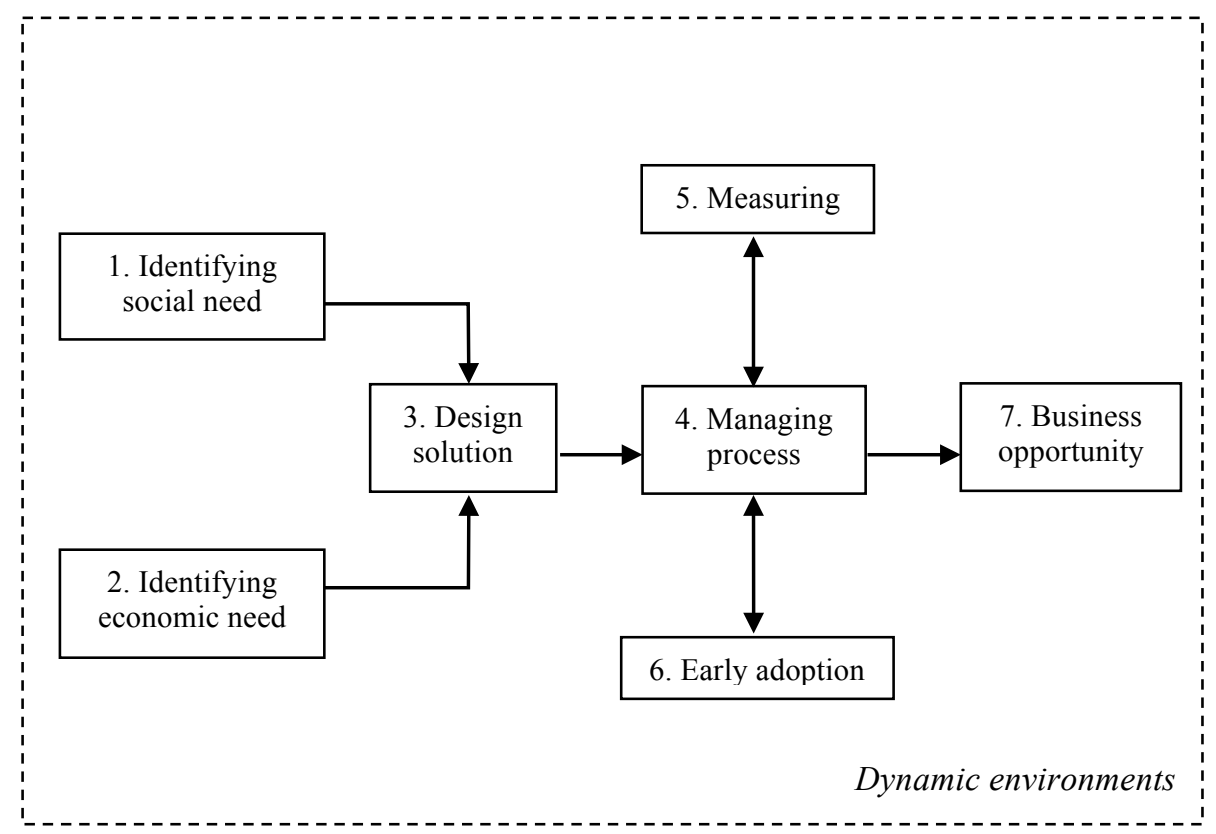

Phase 1 presents that the PPP can identify social needs, based on interviews carried out with some stakeholders of the innovation (e.g. users, citizens, social groups and special groups) in living labs. Phase 2 describes PPP can identify economic opportunities from interviews with public and private organisations (i.e. potential buyers) in order to prepare the requirements to check if also social needs could be achieved and not only economics needs. Phase 3 demonstrates the PPP can establish collaboration with local SMEs in order to design a quicker solution (i.e. in terms of the go-to-market strategy) with higher impact (i.e. in terms of production of social and economic impact thorough society and to the organisations that are the main stakeholders of each of the mobile applications), and with the participation of users codesign the social innovation.

Phase 4 shows that the PPP can be held responsible to implement and to manage the innovation process (i.e. sub-contracting of SMEs to develop some customised part of the service solution). Phase 5 is realised by the PPP through the measuring the impact of social innovation 
(i.e. survey with social relevant groups; single users based on crowdsourcing techniques and also based on surveys with the managers of all the PPP member organisations). Phase 6 presents the modelling of early adoption of innovation (i.e. with community of users in the living labs), which must be done considering the high variability presented by dynamic environments (i.e. in terms of rapid changes in technology life cycles and also the user requirements). Finally, phase 7 presents the business opportunities, in which the PPP must take into consideration the social and economic impact of the innovation on the local territory. In this last phase, the stakeholders can evaluate the possibilities to increase the diffusion rate of the social innovation through spreading this social innovation through the communication channels of large ICT networks, such as the business development network of the EIT ICT Labs around the six centre of excellence.

Furthermore, this research identified that users assumed several different roles over this model, in particular the category defined as special groups. These special groups include: data providers, service providers, service developers and relevant social actors. The model also enables PPP to adopt new alternatives for the formalisation of support of SMEs in the design and development of social innovation. These alternatives could provide faster delivery of public sector services than the traditional ways. The model supports PPP in organising collaborative processes, and, in enabling the diffusion of social innovation in dynamic environments.

This model can play an integral role in supporting SMEs in the development of innovative solutions enabling them to cope with social needs of specific living labs, within dynamic environments. From the model, SMEs will also be able to explore large European markets, throughout the cities where the EIT ICT Labs are established. SMEs can carry out this exploration in order to develop mobile applications that leverage service innovations in several application domains, such as retail, finance, sports and leisure. Citizen participation was verified by the collection of open data and social data that was used to analyse the status and the dynamics of the people in a city. It has been done by the PPP in order to improve the quality of public services offered by the local government.

\subsection{The propositions for further research}

From this model, researchers can explore the phenomenon of social innovation in dynamic environments from the perspective of public-private partnership. This point of view enable researchers to be mind-oriented to explore social innovation that could achieve social and economic value, thus increasing production value for citizens, companies, research centres and local governments. At the same time researchers can explore the study of temporary advantage and early adoption of social innovation. The following four propositions are suggested for further research: 
Proposition 1: PPP that creates value through organisational structures and flexible processes, to manage innovation and avail the opportunities that are provided by ICT, increase the success rate of social innovations enabled by shared data in dynamic environments.

Proposition 2: PPP that involves users in the development of formal routines for the engagement of people with different roles (i.e. citizens; expert users or crowds), enabling collaborative innovation structures, increases the success rate of social innovations enabled by shared data in dynamic environments.

From these suggestions, PPP can be organised to address the traditional vocation of local governments, which is the production of direct services and also develop social innovations enabled by shared data. In this context, SMEs can achieve special agreements with the "hubcompany" in the innovation process, such as Trento RISE, in order to participate in collaborative open processes to carry out joint development of the innovation with the PPP. In this sense, ICT service innovation enables PPP engaging a large number of actors to design and develop service innovation within dynamic environments. This could be done in order to make the delivery of services for citizens more user-centred, where PPP can increase the participation of citizens in democratic decisions about priorities in terms of new services that can have impact on the improvement of the quality of life. From this, PPP can develop services for citizens and increase transparency, in a way in which citizens can develop better ideas about the public expenditures for service innovation.

Proposition 3: PPP that explores temporary advantage to enable the increase of responsiveness, in order to bright about changes within the external environment through flexible intervention of local governments in ICT with direct results of wellbeing of citizens, increases the success rate of social innovations enabled by shared data in dynamic environments.

Proposition 4: PPP that develop structures for early adoption of innovation among target users in order to enable diffusion in local territories and across countries, enable the competition between SME in terms of enhanced technological features, and increases the success rate of social innovations enabled by shared data in dynamic environments.

From these suggestions, PPP can manage ICT platforms, with innovative communities of users and with integration of new knowledge in the innovation process, which came from several different sources. In this context, social innovations enabled by shared data are an alternative for the creation of temporary advantage, to growth the early adoption rate and increase the sustainable position of SMEs in living labs, especially in times of financial crisis. The shared data phenomenon can enable SMEs to re-use information that is obtained from public and private 
companies. Once PPP enables these initiatives, more users and SME's will participate in the development of social innovation to increase the well-being of citizens. At the same time, shared data enable SMEs to develop innovative solutions to guarantee temporary advantage, which is required in dynamic environments.

\section{DISCUSSION AND CONCLUSIONS}

This research built a model for the development of social innovation enabled by shared data. This model has been empirically designed from the dynamic environment of living labs in the Trentino territory in Italy. It is based on new ways of carrying out PPP, mainly involving SMEs, users and innovative communities for the success of the innovation process. This could improve the social innovation capacity of local governments to improve the well-being of citizens. In the same way, companies could improve the rate of early adoption of social innovation and could also sustain a temporary advantage.

In order to answer the research questions, the model also presents fundamental aspects of the public sector. These aspects are based on the promotion of transparency, engagement in social participation, public integrity, and organisation of services for citizens. Furthermore, the model allows stakeholders to verify both the performance of the offered social innovation from specific social requirements, and the diffusion of these into the ecosystems.

This research contributes to the social entrepreneurship and innovation fields through an analysis of the development of social innovation in dynamic environments. In addition, this work contributes to the open innovation field by exploring the process in which public-private partnerships are structured to support SMEs to be competitive within dynamic environments.

This research extends the research of Battisti (2012) for the development of social innovation by integration of a new driver (i.e. temporary advantage), which can be included with the set of the four drivers (i.e. Table 5.1) that a social innovation must have within dynamic environments. From this perspective, the shared data phenomenon is useful in supporting the participation of SMEs and citizens, and, is crucial for the virtuous cycle between these and the PPP's. This user engagement could guarantee the most appropriate management model for the entire process of service innovation, and PPP could achieve the main goal of delivering innovative services in order to improve quality of life. The shared data phenomenon also enables new alternatives for collaborative development of models for PPP, which aids the managers in improving the understanding of social innovation in dynamic environments.

For theoretical contributions, this research supports the understanding of the process in which PPP can explore the social and economic needs of citizens and stakeholders to further explore the phenomenon of shared data. This must be done in order to develop communication channels 
with citizens, SME, large companies and other local public bodies. Based on this understanding, the SME could express their needs and could be engaged in the community responsible for designing service innovation. In order to manage service innovation more efficiently, the PPP could better explore new market opportunities, in order to improve the traditional way of production of services for the citizens.

For practical implications, this research suggests that PPP could utilise these findings in the development of initiatives for engaging the citizens and to support SMEs in the development of social innovation that increases the capacity of companies to succeed within dynamic environments, and to retain temporary advantage. The implications regarding economic growth of the local territory suggest that SMEs could use these findings to choose the most prominent local territories, e.g. in terms of PPP engagement with the growth of SME, to establish their activities. Some PPP's can be more suitable in supporting SMEs through formal process of social innovation, especially enabled by shared data.

This research also contributes in analysing the citizens' roles during the participatory process of social innovation. This process could support the PPPs to aid the citizens in improving selforganisation for several activities, such as planning routes for taking the bus; planning visits to museums; sharing bikes and cars and exploring sport competitions. Citizens could also directly benefit from the service innovation enabled by shared data, as they are engaged in the service design of new solutions for real life needs, since the early beginning of the innovation process.

Moreover, this process when strongly supported by PPP can enable high levels of service diffusion, such as mobile application for planning traffic transportation. SMEs based in the special territorial locations (i.e. in this case in the Trentino territory) can gain temporary advantage over competitors by designing and developing social innovation for commercialisation in other European markets (e.g. Germany, France, Sweden, Finland and Netherlands); in order to achieve faster innovation diffusion and inclusion of citizens in participatory processes. The extremely short time-to-market of Apps in large cities enable citizens to suit their requirements in order to improve their quality of life, during the use of the Apps. This new model could be fundamental for SMEs, once they aim to compete in European markets, in order to address social needs. Several social needs could be explored; for instance, the urban environment in large European cities, which currently is very crowded due to the population growth, which means increasing problems that must be managed by local governments.

The main limitation is concerned with the data collection process of clinical inquiry and case study, which were carried out mainly though interaction with the key actors in Trentino. This process does not enable the analyses for assessment of the level of engagement of citizens and SMEs in the innovation process. Another limitation is that it was not possible to measure the level of quality of life of citizens provided by the social innovations from the data collected. Hence, further research is suggested with subsequent data collection in the form of surveys and 
quantitative analyses, in order to understand business opportunities and social needs. Finally, this research suggests the following subjects as avenues for further investigation:

i. Absorptive capacity in social innovation: PPP could implement strategies and could formalise continuous collaboration with users, in order to internalise user information and to enable flexible innovation process based on social needs.

ii. Crowdsourcing for social innovation: The ecosystems of social innovation, once managed by PPP, could guarantee the use of new ideas that come from several different kinds of people and may occur based on crowdsourcing platforms.

iii. Crowdfunding for social innovation: PPP could manage crowdfunding techniques in order to support SMEs in funding social innovation and then facilitate the temporary advantage of these SMEs when launching Apps in the mobile markets.

\section{ACKNOWLEDGEMENTS}

I would like to thank Professor Fausto Giunchiglia at the University of Trento for the helpful suggestions to support my $\mathrm{PhD}$ thesis and especially for the intensive discussions about social innovation enabled by ICT. I am very grateful to Professor Mariano Corso and Professor Davide Chiaroni at Politecnico di Milano, for their comments and suggestions which proved helpful in improving this paper. Also thanks to the Editor and to the two anonymous reviewers of the IJSEI. I am very grateful to the all managers for the interviews and for full access to information provided by them during the entire research period. I am grateful to Trento RISE Association for complete access to information regarding shared data in Trentino. I am also grateful for the financial support of Politecnico di Milano, regarding the presentation of the very early part of this research in the 5th ISPIM Innovation Symposium in Seoul, Korea.

\section{REFERENCES}

Austin, J., Stevenson, H., and Wei-Skillern, J. (2006). Social and commercial entrepreneurship: same, different, or both?. Entrepreneurship theory and practice, Vol.30, No.1, pp.1-22.

Bates, S. M. (2012). The social innovation imperative: create winning products, services, and programs that solve society's most pressing challenges. The McGraw-Hill, Inc. New YorkUS.

Battisti, S. (2012). Social innovation: the process development of knowledge-intensive companies, Int. J. Services Technology and Management, Vol. 18, Nos. 3/4, pp. 224-244. 
Belleflamme, P., Lambert, T. and Schwienbacher, A. (2013). Crowdfunding: Tapping the right crowd, Journal of Business Venturing. Article in press. http://dx.doi.org/ 10.1016 /j.jbusvent.2013.07.003.

Bessant, J. (2009). The future of innovation is challenging the frontiers of innovation. In: Von Stamm, B. and Trifilova, A. The Future of Innovation. 1st ed., pp. 42-43. Gower Publishing Limited, Surrey, England-UK.

Bhattacharya, S., Krishnan, V., and Mahajan, V. (1998). Managing new product definition in highly dynamic environments. Management Science, Vol. 44, No.11-Part-2, pp. S50-S64.

Bogers, M. and West, J. (2012). Managing distributed innovation: strategic utilization of open and user innovation. Creativity and Innovation Management, Vol. 21, No.1, pp. 61-75.

Bogers, M., Afuah, A. and Bastian, B. (2010). Users as innovators: A review, critique and future research directions. Journal of Management, Vol. 36, No.4, pp. 857-875.

Cameron, H. (2012). Social entrepreneurs in the social innovation ecosystem. In: Nicholls, A. and Murdock, A. Social Innovation: Blurring Boundaries to Reconfigure Markets. 1st ed. pp.199-220. Palgrave Macmillan Ltd. Basingstoke-UK.

Chiesa, V. and Frattini, F. (2011). Commercializing technological innovation: learning from failures in high-tech markets. Journal of Product Innovation Management, Vol. 28, No. 4, 437-454.

Colombo, G., Buganza, T., Klanner, I. M. and Roiser, S. (2013). Crowdsourcing Intermediaries And Problem Typologies: An Explorative Study. International Journal of Innovation Management, Vol.17, No.2, art. no. 1350005.

D'Aveni, R. A., Dagnino, G. B., and Smith, K. G. (2010). The age of temporary advantage. Strategic Management Journal, Vol.31, No.13, pp.1371-1385

Davis, J. P., Eisenhardt, K. M., and Bingham, C. B. (2009). Optimal structure, market dynamism, and the strategy of simple rules. Administrative Science Quarterly, Vol. 54, No.3, pp.413-452.

Dell'Era, C. and Verganti, R. (2011). Diffusion processes of product meanings in designintensive industries: determinants and dynamics. Journal of Product Innovation Management, Vol.28, No.6, pp.881-895.

Ding, L., Peristeras, V. And Hausenblas, M. (2012). Linked open government data. IEEE Intelligent Systems, Vol. 27, No. 3, pp. 11-15.

Estellés-Arolas, E. and González-Ladrón-De-Guevara, F. (2012). Towards an integrated crowdsourcing definition. Journal of Information Science, Vol.38, No.2, pp. 189-200.

Giannopoulou, E., Ystrom, A. and Ollila, S. (2011). Turning open innovation into practice: open innovation research through the lens of managers. International Journal of Innovation Management, Vol. 15, No. 03, pp. 505-524.

Harrisson, D., Klein, J-L and Browne, P.L. (2010). Social innovation, social enterprise and services. In: Gallouj, F. and Djellal, F. The Handbook of Innovation and Services: A Multidisciplinary Perspective. 1st Ed. pp. 197-218. Edward Elgar Publishing Ltd. CheltenhamUK.

Hsieh, K-N. and Tidd, J. (2012). Open versus closed new service development: The influences of 
project novelty. Technovation, Vol. 32, No. 11, pp. 600-608.

Jespersen, K. R. (2011). Online channels and innovation: are users being empowered and involved? International Journal of Innovation Management, Vol. 15, No. 06, pp. 1141-1159.

Katzy, B.R., Pawar, K.S. and Thoben, K-D. (2012). Editorial: A Living Lab Research Agenda. Int. J. Product Development, Vol.17, Nos.1/2, pp.1-7.

Lehtonen, M. and Tuominen, T. (2011). Multiple voices of the user in public sector services. In: Sundbo, J. and Toivonen, M. User-Based Innovation in Services. 1st edition. pp: 227-250. Edward Elgar Publishing Limited. Cheltenham-UK.

Martin, S. and Scott, J.T. (2000). The nature of innovation market failure and the design of public support for private innovation. Research Policy, Vol.29, Nos. 4/5, pp. 437-447.

Miller, T. L., Grimes, M. G., McMullen, J. S., and Vogus, T. J. (2012). Venturing for others with heart and head: how compassion encourages social entrepreneurship. Academy of Management Review, Vol.37, No.4, pp.616-640.

Mollick, E. (2014). The dynamics of crowdfunding: An exploratory study. Journal of Business Venturing, Vol. 29, No.1, pp.1-16.

Mulgan, G. (2012). The theoretical foundations of social innovation. In: Nicholls, A. and Murdock, A. Social Innovation: Blurring Boundaries to Reconfigure Markets. 1st ed., pp. 3365. Palgrave Macmillan Ltd. Basingstoke-UK.

Nicholls, A. and Murdock, A. (2012). The nature of social innovation. In: Nicholls, A. and Murdock, A. Social Innovation: Blurring Boundaries to Reconfigure Markets. 1st ed., pp. 130. Palgrave Macmillan Ltd. Basingstoke-UK.

O’Reilly, T. (2010). Government as a platform. In: Lathrop, D. and Ruma, L. Open government. Transparency, participation, and collaboration in practice. 1st Ed. O'Reilly Media, Inc., Sebastopol-CA. pp. 11-42.

Okpara, J. O. and Halkias, D. (2011). Social entrepreneurship: an overview of its theoretical evolution and proposed research model. International Journal of Social Entrepreneurship and Innovation, Vol.1, No.1, pp.4-20.

Ordanini, A., Miceli, L., Pizzetti, M., and Parasuraman, A. (2011). Crowd-funding: transforming customers into investors through innovative service platforms. Journal of Service Management, Vol.22, No.4, pp.443-470.

Ormiston, J. and Seymour, R. (2011). Understanding value creation in social entrepreneurship: the importance of aligning mission, strategy and impact Measurement, Journal of Social Entrepreneurship, Vol. 2, No.2, pp.125-150.

Perks, H., Gruber, T. and Edvardsson, B. (2012). Co-creation in radical service innovation: a systematic analysis of microlevel processes. Journal of Product Innovation Management, Vol.29, No.6, pp. 935-951.

Posen, H. E., and Levinthal, D. A. (2012). Chasing a moving target: Exploitation and exploration in dynamic environments. Management Science, Vol.58, No.3, pp. 587-601.

Ratten, V. (2012). A theoretical framework of entrepreneurship and innovation in healthcare organisations. International Journal of Social Entrepreneurship and Innovation, Vol.1, No.3, pp.223-238. 
Ratten, V. (2013). Social e-entrepreneurship and technological innovations: The role of online communities, mobile communication and social networks. International Journal of Social Entrepreneurship and Innovation. Forthcoming.

Remneland-Wikhamn, B., Ljungberg, J., Bergquist, M. and Kuschel, J. (2011). Open innovation, generativity and the supplier as peer: the case of iphone and android. International Journal of Innovation Management, Vol. 15, No. 01, pp. 205-230.

Scarlato, M. (2012). Social enterprise and development policy: evidence from Italy. Journal of Social Entrepreneurship, Vol.3, No.1, pp.24-49.

Schein, E. H. (2008). Clinical inquiry/research. In P. Reason and H. Bradbury (Eds.), Handbook of action research. 2nd ed. pp. 266-279, Sage, London.

Sheremata, W. A. (2000). Centrifugal and centripetal forces in radical new product development under time pressure. Academy of management review, Vol. 25, No. 2, pp. 389-408.

Sheremata, W. A. (2004). Competing through innovation in network markets: strategies for challengers. Academy of Management Review, Vol.29, No.3, pp.359-377.

Sirmon, D. G., Hitt, M. A. and Ireland, R. D. (2007). Managing firm resources in dynamic environments to create value: Looking inside the black box. Academy of Management Review, Vol.32, No.1, pp. 273-292.

Sundbo, J. and Toivonen, M. (2011). User-Based Innovation in Services. Edward Elgar Publishing Limited. Cheltenham-UK.

Talke, K. and Hultink, E.J. (2010). Managing diffusion barriers when launching new products, Journal of Product Innovation Management, Vol. 27, No. 4, pp. 537-553.

Tidd, J. (2009). The future of innovation is the basis for social and economic change. In: Von Stamm, B. and Trifilova, A. The Future of Innovation. 1st ed., pp. 206-207. Gower Publishing Limited, Surrey, England-UK.

Wouters, M. (2010). Customer value propositions in the context of technology commercialization. International Journal of Innovation Management, Vol. 14, No. 06, pp. 1099-1127.

Yin, R.K. (2009). Case study research: design and methods. 4th ed. Applied Social Research Methods. Vol.5. Sage Publications, Thousand Oaks, CA. 